\title{
Construction of a Questionnaire of the Attitude towards Homosexuality among Chinese College Students
}

\author{
Rui Jiang \\ School of psychology \\ Central China Normal University \\ Wuhan 430079,Hubei Province, China
}

\author{
Chuang Gao \\ Key Laboratory of Adolescent Cyberpsychology and \\ Behavior \\ Central China Normal University \\ Wuhan 430079, Hubei Province, China
}

\begin{abstract}
Objectives: To develop a questionnaire of the attitude towards homosexuality, which can be adapted to college students, and discuss its reliability and validity. Methods: Through the reference of massive relevant studies and the current questionnaires towards homosexuality in China, the questionnaire was developed relying on the three-factor model of attitude. We conducted our research among 169 students as our pre-test. After the confirmation of our questionnaire, it was conducted again among 251 students. Results: the formal questionnaire contained 12 items and 3 components which could totally explain $\mathbf{7 1 . 6 0 3 \%}$. They could separately explain $53.36 \%$, $9.81 \%$ and $8.433 \%$. The scale had NFI 0.97, NNFI 0.98, CFI 0.98, RMSEA 0.069. The Cronbach's $\alpha$ coefficient of the total-scale was 0.922 , the split-half reliability was 0.871 . Conclusion: The "Questionnaire of The attitude towards homosexuality among Chinese college students" is good enough to be applied to the concerning research in the future.
\end{abstract}

Keywords-homosexuality; college students; questionnaire; attitude

\section{INTRODUCTION}

As a special group, the homosexuality has always been receiving the concerns of the society. As an orientation, homosexuality refers to "an enduring pattern of or disposition to experience sexual behavior or sexual interest" primarily or exclusively to people of the same sex [1]. In 1952, when the American Psychiatric Association published its first Diagnostic and Statistical Manual of Mental Disorders, homosexuality was defined as a sociopath personality disturbance, however in its second edition in 1968, homosexuality was classified as a sexual deviation [2]. Homosexuality, once was thought to be abnormal, is now drawing extensive concern and gradually accepted by the public. It was not until 1973 that the American Psychiatric Association issued a statement to remove homosexuality from the disease classification in the third edition of "Diagnostic and Statistical Manual of Mental Disorders" (DSM-3). In 2001, the definition of homosexuality was revised from mental disorders as well in the Chinese Classification of Mental Disorders (CCMD-3). These all identify the social progress and social tolerance.

Although people have a better understanding of homosexuals, not everyone can respect and accept them. Homosexuals are still facing unfairness and hardship.
Pilkington, N.W et al. conducted a survey in the United States. $80 \%$ of homosexuals had been verbally attacked by their classmates. Males experienced more verbal insults than females. One third of all had been thrown with objects and $10 \%$ had been physically assaulted for their sexual orientation. $36 \%$ of homosexuals said they had been verbally insulted by an immediate family member at least once[3].

It is precisely because of those discriminations and some other unfairnesses that homosexuals are more vulnerable to mental illness. They need more support from their family and society. For lesbians and gay men, in particular, a study conducted by Vickie M Mays and Susan D Cochran, have shown that they might be exposed to higher levels of risk of psychological stress and mental disorder than heterosexuals[4]. Another survey reported that gay youth experienced significantly higher levels of suicidal ideation and more frequent depressive thoughts [5]. For homosexuals, the most important thing is support. Gay men who were more satisfied with the social support were less likely to show increased depression 1 year later [6].

In recent years, more and more attention has been paid to homosexuals as a comfort, for they have suffered so much. People had a new understanding of this problem and showed their blessings to homosexuals. It was reported that even in some countries, policies were eased to allow homosexual marriage. Similarly, a boom of homosexual novels and words rapidly emerged on Chinese Internet. These have all attributed to the change of people's attitude. All above have been shown that great importance must be attached to the understanding of people's attitudes towards homosexuality.

It is widely believed that the attitude is the relatively stable and evaluative tendency of psychological reactions that individuals hold for a certain object [7]. Attitude consists of three elements of cognition, affection and behavior, according to Freedman. Any excitation of one element will excite the corresponding reaction of the rest two elements, which is the consistency of these three elements: feeling (ethics and values), affection (like or dislike, love or hate), and intention (deliberation and attempt).

Whether homosexuals, this special group, can live in society by whatever ways they deem appropriate and normal, is not the only determinant of themselves and psychiatrists' opinions on homosexuality, but also to a large extent of the public recognition [8]. College students, known as the representatives of intelligence and quality, are of strong 
plasticity and more likely to accept new ideas and concepts, especially in such open cultural environment. Their cognitions and attitudes on homosexuality are an important direction for development of overall cognition and attitude in society [1]. It was from Chinese college students that the study was conducted and the questionnaire was developed, the questionnaire was wished to be a good tool for the future study, as well as the understanding on the cognition and attitude on homosexuals of whole society.

\section{METHOD}

\section{A. Subjects}

The survey was conducted through the paper questionnaires or the online questionnaires, and 381 valid questionnaires were received. The volunteers were Chinese college students from freshman year to senior year.169 pretest questionnaires were distributed and 150 valid questionnaires were recalled. Of all the participants, $47 \%$ were male and $53 \%$ were female(21 freshmen 88 sophomores 20 juniors and 21 seniors; $21 \%$ liberal arts students, $73 \%$ science students, $6 \%$ art and sport students). 251 formal questionnaires were distributed and 231 valid questionnaires were recalled, including $40 \%$ male participants and $60 \%$ female participants. (21 freshmen 13 sophomores 115 juniors and 32 seniors;29\% liberal arts students, $68 \%$ science students, $3 \%$ art and sport students).

\section{B. Formation of the questionnaire}

According to the three-factor model of attitude in social psychology, the questionnaire was constructed from three aspects: cognition, affection and behavior. Through the reference of massive relevant studies and the current questionnaires towards homosexuality home and abroad, researchers selected and revised some items from 4 researches: "Comparison Study of College Students' Implicit Attitude and Explicit Attitude to Homosexuality" [9], "Research on the Attitude of Normal University Students to Homosexuality and Attitude Change" [10], "The Relationship between Competency and Management Performance of the Manager in an Enterprise" [11], and "Theory Construction of the Attitudes Toward Gay Men and Lesbians in Chinese Context and Assessments in College Students" [12]. After Some good items were kept and modified, a 30-item pre-test questionnaire of the attitude towards homosexuality had been formed.

In the pre-test questionnaire, 16 items are negative items. A five-point Likert-type scale was adopted (1="very disagree" to $5=$ "very agree"), with higher scores meaning support to homosexuality, whereas the reverse was indicative of objection. After the exploratory factor analysis and the item analysis on the questionnaire, some items were deleted and revised. Finally, a 12-item questionnaire of the attitude towards homosexuality among Chinese college was constructed.

\section{Item Analysis,Reliability Analysis and Validity Analysis}

This study tested correlation between the score of every item and the total score to describe the item Discrimination. The Cronbach's alpha and split-half reliability were adopted as the index of reliability. Exploratory factor analysis and confirmatory factor analysis were used to test construct validity.

\section{Statistical Methods}

The construction of the questionnaire was verified through the exploratory factor analysis, confirmatory factor analysis and item analysis

\section{RESULTS}

\section{A. Exploratory Factor Analysis on the Original 30 Items}

169 volunteers participated in the pre-test survey, and 150 questionnaires were valid. The exploratory factor analysis on the original 30 item was conducted. The factors were extracted by principal component analysis and rotated by Varimax. The items were reserved with an Eigenvalue $>1$. Results are displayed in Table 1.

The KMO value is $0.944, \mathrm{P}<0.01$, which indicates that this questionnaire is suitable for the Exploratory Factor Analysis. On the basis of the result of the first exploratory factor analysis on questionnaire, items with low factor loadings or multi-loadings were removed. In addition, two questions with duplicated semantics with other sentences were eliminated. Finally 12 items were left, including 8 positive items and 4 negative items.

\section{B. Item Analysis}

The discrimination of every item was analyzed. Item-total correlation was adopted as the index of discrimination. Results are displayed in Table 2.

Through the statistics from item total correlations, it was found that The values of the 12 items were higher than 0.6 , which indicated all the items were up to standard.

\section{Exploratory Factor Analysis on the left 12 items}

A second Exploratory Factor Analysis was conducted. There were three components that could explain 71.603 of the total variance in this questionnaire. The three components could explain $53.36 \%, 9.81 \%$ and $8.433 \%$ of the variance separately. Results are displayed in Table 3.The three components were named cognitive preference $(\mathrm{CP})$, emotional preference (EP) and behavior preference (BP) via original dimension. 
TABLE I. THE FIRST EXPLORATORY FACTOR ANALYSIS ON THE QUESTIONNAIRE OF THE ATTITUDE TOWARDS HOMOSEXUALITY

\begin{tabular}{|c|c|c|c|c|}
\hline Item & Factor1 & Facto2 & Facto3 & Facto4 \\
\hline 21 & 0.729 & & & \\
\hline 22 & 0.695 & & & \\
\hline 7 & 0.691 & 0.406 & & \\
\hline 11 & 0.683 & & & \\
\hline 12 & 0.676 & & 0.407 & \\
\hline 10 & 0.664 & & & \\
\hline 16 & 0.660 & & & \\
\hline 9 & 0.648 & & & \\
\hline 8 & 0.645 & & & \\
\hline 6 & 0.629 & & 0.424 & \\
\hline 5 & 0.611 & 0.529 & & \\
\hline 23 & 0.583 & 0.469 & & \\
\hline 19 & 0.579 & 0.483 & & \\
\hline 25 & 0.516 & 0.469 & & \\
\hline 2 & & 0.694 & & \\
\hline 4 & & 0.688 & & \\
\hline 3 & & 0.639 & & \\
\hline 1 & & 0.635 & & \\
\hline 18 & 0.567 & 0.588 & & \\
\hline 20 & & 0.525 & & 0.402 \\
\hline 17 & & 0.403 & & \\
\hline 27 & & & 0.735 & \\
\hline 26 & & & 0.731 & \\
\hline 29 & & 0.415 & 0.679 & \\
\hline 30 & & & 0.664 & \\
\hline 24 & & 0.422 & 0.663 & \\
\hline 28 & & & 0.565 & \\
\hline 15 & & & & 0.767 \\
\hline 13 & & & & 0.630 \\
\hline 14 & & & & 0.474 \\
\hline Eigenvalues & 15.484 & 1.758 & 1.421 & 1.036 \\
\hline Variance $(\%)$ & 51.613 & 5.860 & 4.736 & 3.454 \\
\hline Cumulative (\%) & 51.613 & 57.473 & 62.209 & 65.663 \\
\hline $\begin{array}{l}\text { Kaiser-Meyer-Olkin } \\
\text { Measure of } \\
\text { Sampling Adequacy } \\
\text { Bartlett's Test of } \\
\text { Sphericity Sig. } \\
\end{array}$ & $0.000 * * *$ & & & \\
\hline
\end{tabular}

$* * * . \mathrm{P}<0.001$.

Note. Factor loadings greater than 0.400 were unmarked. Item1,2,6,8,10,11,13,21,26,27 were selected from "Comparison Study of College Students' Implicit Attitude and Explicit Attitude to Homosexuality"[9]. Item 3,5,7,15,16,17,18,20,23,25,29 were revised from "Research on the Attitude of Normal University Students to Homosexuality and Attitude Change"[10]. Item 14, 22, 30 were selected from"The Relationship between Competency and Management Performance of the Manager in an Enterprise"[11]. Item 9,12,24 were selected from"Theory Construction of the Attitudes Toward Gay Men and Lesbians in Chinese Context and Assessments in College Students"[12].
TABLE II.THE ITEM DISCRIMINATION ANALYSIS OF THE QUESTIONNAIRE OF THE ATTITUDE TOWARDS HOMOSEXUALITY

\begin{tabular}{|c|c|}
\hline Item & Discrimination \\
\hline $\begin{array}{l}27 \text { If my homosexual friend asks me to go out, I } \\
\text { will be glad to go. }\end{array}$ & 0.773 \\
\hline 26 I will make friends with homosexuals. & 0.706 \\
\hline 28 I accept homosexual classmates. & 0.692 \\
\hline $\begin{array}{l}30 \text { I'll have a pleasant time at the social meeting } \\
\text { where homosexuals attend. }\end{array}$ & 0.725 \\
\hline $\begin{array}{l}4 \text { I support the establishment of some } \\
\text { homosexual community organizations in } \\
\text { society. }\end{array}$ & 0.713 \\
\hline $\begin{array}{l}2 \text { I think Chinese government should legislate to } \\
\text { allow homosexual marriage. }\end{array}$ & 0.713 \\
\hline $\begin{array}{l}3 \text { Under no circumstances could homosexuals' } \\
\text { sexual orientation be discriminated against at } \\
\text { work. }\end{array}$ & 0.693 \\
\hline $\begin{array}{l}1 \text { I believe that the love of homosexual is the } \\
\text { same as the love of heterosexual. They are both } \\
\text { normal. }\end{array}$ & 0.826 \\
\hline $\begin{array}{l}16 \text { Homosexuality is harmful to society for it } \\
\text { breaks the natural boundary between genders. }\end{array}$ & 0.737 \\
\hline 10 Homosexuality is a sin. & 0.731 \\
\hline $\begin{array}{l}9 \text { I'll feel upset if one of my close friends is a } \\
\text { homosexual. }\end{array}$ & 0.710 \\
\hline $\begin{array}{l}21 \text { I indeed have the feeling of disgust to } \\
\text { homosexuals }\end{array}$ & 0.728 \\
\hline
\end{tabular}

Note. Discrimination originates from the item-total correlation index. Item 1,2,10,21,26,27 were selected 'Comparison Study of College Students' Implicit Attitude and Explicit Attitude to Homosexuality"[9]. Item 16 were revised from "Research on the Attitude of Normal University Students to Homosexuality and Attitude Change"[10]. Item 30 were selected from "The Relationship between Competency and Management Performance of the Manager in an Enterprise"[11]. Item 9 were selected from "Theory Construction of the Attitudes Toward Gay Men and Lesbians in Chinese Context and Assessments in College Students"[12]

TABLE III. THE FACTOR LOADING OF THE QUESTIONNAIRE OF THE ATTITUDE TOWARDS HOMOSEXUALITY

\begin{tabular}{cccccccc}
\hline $\mathrm{C} 1$ & $\mathrm{CP}$ & & $\mathrm{C} 2$ & $\mathrm{EP}$ & & $\mathrm{C} 3$ & $\mathrm{BP}$ \\
\cline { 1 - 2 } \cline { 6 - 7 } \cline { 6 - 7 } item & loading & & item & loading & & item & loading \\
\hline 1 & 0.699 & & 9 & 0.748 & & 26 & 0.850 \\
2 & 0.736 & & 10 & 0.768 & & 27 & 0.852 \\
3 & 0.756 & & 16 & 0.784 & & 28 & 0.718 \\
4 & 0.792 & & 21 & 0.700 & & 30 & 0.690 \\
& & & & & & 21 & 0.454
\end{tabular}

The result of the Exploratory Factor Analysis (TABLE 3) revealed that item 21 was ambiguous with its loadings both on Component 2 and Component 3. However, due to its high loading on Component 2, the statement of item 21 was modified to make sure that item 21 only had loading on Component 2.The sentence "I indeed have the feeling of disgust to homosexuals" which was also thought belonging to the behavior preference had been changed to "homosexuals give me a sense of disgust"

\section{Reliability Analysis}

A 12-item questionnaire contained 12 questions was used to test the college students after 3 month. 251 formal questionnaires of the attitude towards homosexuality were distributed and 231 valid questionnaires were recalled. The questionnaire of the attitude towards homosexuality's coefficient alpha was 0.922 and the split-half reliability was 0.871. The Cronbach's coefficient of the cognitive preference, 
emotional preference and behavior preference were 0.815 , 0.760 , and 0.831 .

\section{E. Confirmatory Factor Analysis}

To exam the three-factor structure of the questionnaire of the attitude towards homosexuality, a confirmatory factor analysis was conducted 3 month later after the revision of the questionnaire. The LISREL 8.8 was used to explore the construction of the questionnaire. The result of the CFA were: $\mathrm{x} 2=105.940, \mathrm{df}=51, \mathrm{NFI}=0.97, \mathrm{NNFI}=0.98, \mathrm{CFI}=0.98, \mathrm{RMSEA}=$ 0.069.(for well-fitting models, NFI $>0.90$, NNFI $>0.90$ and CFI $>0.90$, RMSEA<0.08). Synthesizing the reliability analysis, the exploratory factor analysis and the confirmatory factor analysis in this study, the construction of our questionnaire was suitable for the research of homosexuality in the future.

\section{DISCUSSION}

Through systematical review and analysis of the current Chinese questionnaires and previous results, the questionnaire in this paper was established via the three-factor model of attitude which applied to Chinese college students well. The original questionnaire had 30 questions. Then on the basis of exploratory factor analysis some items which had low factor loadings or had loadings on two factors were removed, as well as that of duplicated semantics with other sentences. Finally, a 12-item with three components questionnaire of the attitude towards homosexuality was formed after the modification of inappropriate expression of items. The three components, named cognitive preference, emotional preference and behavior preference, could explain 53.36\%, 9.81\% and $8.433 \%$ of the variance. Among them, the behavior preference had the largest variance meaning whether to accept or willing to get along with homosexuals.

Item analysis on questionnaire was conducted. We chose item-total correlation as discrimination, and the discrimination of each item had reached more than 0.69 . They all reached the standard of psychometrics and proved to be reasonably good. The questionnaire of the attitude towards homosexuality's coefficient alpha was 0.922 and the split-half reliability was 0.871 . The Cronbach's coefficient of the cognitive preference, emotional preference and behavior preference were 0.815 , 0.760 , and 0.831 . These results suggested that the formal questionnaire had a clear structure of three factors. All the items only had one loading on their component except one item which was revised afterwards. Each item was a good reflection of the concept to be measured.3 months later, 251 Chinese college students were randomly selected to have the formal measure implemented. A confirmatory factor analysis was conducted to test the three-factor structure of the questionnaire. All results were up to standard, indicating that the model fit the statistics quite well. This survey manifested that the questionnaire of the attitude towards homosexuality was appropriate for Chinese college students.

Questionnaires in this paper were mainly from original questionnaires of publication on the "Comparison Study of College Students' Implicit Attitude and Explicit Attitude to Homosexuality"[9] and adapted from questionnaires of publication on the "Research on the Attitude of Normal University Students to Homosexuality and Attitude Change"'[10], the comparison has been made between them and the results have been obtained as follows. The Cronbach's alpha of Liu's questionnaire was 0.9168 , however in our paper it was slightly higher, 0.922 , which indicated better stability and reliability. The split-half reliability for the former one was between 0.82 to 0.94 while the latter reached 0.871 , a relatively high level of questionnaire compilation in psychology and was higher than the minimum standard of former. However, Liu's questionnaire mainly focused on the comparison between implicit attitude and explicit attitude. Therefore, it's only necessary to meet the need of research, with no need for over pursuit of a very high level and reliability.

The Cronbach's Alpha of questionnaire of Lv Shaobo's research [10] was 0.93, slightly higher than ours, which might due to the amount of subjects. In the first survey of original questionnaire only 169 college students have been tested, the recalled valid questionnaires has amounted to 150 , just reached the standard of exploratory analysis. While in Lv's survey 704 college students have been tested and recalled valid questionnaires was 636. In addition, he didn't divide attitude questionnaires into three dimensions according to the three factor approach of attitude, only two dimensions - one was people's attitude toward male homosexuality and the other was female homosexuality. In this paper the questions have been adapted and not divided into scale of male \& female, also the questionnaire was revised in accordance with the threeelement model of attitude. Therefore the differences in reliability were ineluctable.

Overall this well-designed questionnaire is perfectly satisfactory to the research on affecting factors of college students' attitudes toward homosexuality for it has a good reliability and approach matching. It also creates a solid foundation for the further research on homosexuality in future.

\section{ACKNOWLEDGMENT}

Thank all the participants and co-authors for working on the construction of the questionnaire .This research was financially supported by Social Science Foundation of The Chinese Education Commission grant 15609540.

\section{APPENDIX}

The original 30-item questionnaire (short form) :

1. I believe that the love of homosexual is the same as the love of heterosexual. They are both normal.

2. I think Chinese government should legislate to allow homosexual marriage.

3. Under no circumstances could homosexuals' sexual orientation be discriminated against at work.

4. I support the establishment of some homosexual community organizations in society.

5. Homosexual marriage is ridiculous to me.

6. The inmate behaviors between homosexuals disgust me more than those between heterosexuals.

7. Homosexuality is disgusting.

8. I feel dirty at the thought of homosexuality.

9. I'll feel upset if one of my close friends is a homosexual.

10. Homosexuality is a sin.

11. I'll deliberately avoid staying alone with homosexuals.

12. I try to stay out of homosexuals and not have any interaction with them. 
13. I will speak in defense of homosexuals. And I hope those who don't accept homosexuals to turn to accept them.

14. Working in close cooperation with homosexuals, I feel comfortable.

15. If I find that one of my friends is a homosexual, I am willing to remain our friendship.

16. Homosexuality is harmful to society for it breaks the natural boundary between genders.

17. Homosexuals should not be allowed in the teaching profession.

18. The sex behavior between homosexuals is wrong.

19. I think homosexuals should receive medical treatment and psychotherapy to help them become heterosexuals.

20. Chinese law should allow homosexual to adopt a child

21 . Homosexuals give me a sense of disgust.

22. I feel upset when staying alone with a homosexual.

23. Homosexual sex makes me pretty disgusting.

24. If my teacher is a homosexual, I won't have any special feeling.

25. If I know that my favorite star in entertainment and sports circles is a homosexual, I won't like him or her any more.

26. I will make friends with homosexuals.

27. If my homosexual friend asks me to go out, I will be glad to go.

28. I accept homosexual classmates.

29. If I were the person in charge, I could accept homosexual staff.

30. I'll have a pleasant time at the social meeting where homosexuals attend.

\section{REFERENCES}

[1] Zhang Han, Sun Tingting, and Wang Peng, "An investigation of college students' cognition and attitude to homosexuality," The Chinese Journal of Human Sexuality. 2008,17(9): p.9-12.

[2] Li Huijing, "Mental Health of Homosexuals and Its Influencing Factors ," Science of Social Psychology. 2010,25(4): p.464-469.

[3] Pilkington, N.W. and A.R. D'Augelli, "Victimization of lesbian, gay, and bisexual youth in community settings,"Journal of Community Psychology.1995,23: p.33-56.

[4] Vickie M Mays, Susan D Cochran,"Mental health correlates of perceived discrimination among lesbian, gay, and bisexual adults in the United States,"American Journal of Public Health.2001,91(11) : p.1869.

[5] Nicholas, J. and J. Howard, "Better dead than gay? Depression, suicide ideation and attempt among a sample of gay and straight-identified males aged 18 to 24," Youth Studies Australia, 1998.17: p. 28-33.

[6] Hays, R.B., H. Turner, and T.J. Coates,"Social support, AIDS-related symptoms, and depression among gay men,"Journal of consulting and clinical psychology, 1992. 60(3): p. 463.

[7] Zhang Zhiguang,“ Social psychology,”People's education press, 1996: p.1872.

[8] Tao Lin, Zhou Hong, Liu Rengang, "Investigation of attitudes towards homosexuality among medical staff and college students," Chinese journal of behavioral medical science,2001,10(5):p. 475-477

[9] Liu Wanna, Ma Lijun, Luo Jiajie,"Comparison Study of College Students' Implicit Attitude and Explicit Attitude to Homosexuality,". China Journal of Health Psychology, 2010,18(12):p.1494-1496.

[10] Lv Shaobo, "Research on the Attitude of Normal University Students to Homosexuality and Attitude Change," Hebei Normal University,2009.

[11] Liu Yi, “The relationship between competency and management performance of the manager in an enterprise," Guangzhou University,2011

[12] Yu Yong, Xiao Shuiyuan and Xiang Ying, “ Theory Construction of the Attitudes Toward Gay Men and Lesbians in Chinese Context and Assessments in College Students,"Chinese Journal of Clinical Psychology, 2010,18(2): p.174-176.1 